\title{
Antibiotic consumption and the role of dispensing physicians
}

\author{
M. Filippini ${ }^{*} \quad$ F. Heimsch ${ }^{\dagger} \quad$ G. Masiero ${ }^{\ddagger}$ \\ Published in Regional Science and Urban Economics (2014), 49: 242-251 \\ http://www.journals.elsevier.com/regional-science-and-urban-economics/
}

\begin{abstract}
The benefits of separating drug prescribing and dispensing are still unclear, in particular when drug consumption is characterized by important spillovers. We investigate the role of dispensing physicians in the consumption of antibiotics characterized by two opposite external effects: infection prevention and control, and bacterial resistance. We model the interaction between competing physicians (with and without dispensing of drugs) and patients exposed to bacterial infections and show that spatial effects of consumption may generate ambiguous results. Then, we propose an empirical exercise which exploits data from small geographic areas in Switzerland where two regimes - prescribing physicians and dispensing physicians - are possible. We consider spatial aspects of antibiotic consumption by means of combined spatial lag and spatial error econometric estimators for panel data (SARAR models). We find evidence that dispensing practices increase antibiotic use after controlling for determinants of demand and access, and spatial effects. Whether dispensing practices lead to an increase of antibiotic consumption beyond socially optimal levels is unclear and requires further research.
\end{abstract}

JEL classification: I11; I18; D12; D21; D43; D81; D82

Keywords: Physician dispensing, Prescribing behaviour, Antibiotic use, Consumption spillovers, Spatial effects.

\footnotetext{
${ }^{*}$ Institute of Economics (IdEP), University of Lugano; ETH Zurich, Switzerland.

${ }^{\dagger}$ ETH Zurich, Switzerland.

${ }^{\ddagger}$ Department of Engineering, University of Bergamo, Italy; Institute of Economics (IdEP), University of Lugano, Switzerland. Corresponding author. Tel.: +41058666 4731; fax: +41058666 4733. E-mail address: giuliano.masiero@usi.ch. Support from the Swiss National Science Foundation is acknowledged. We are grateful to Karine Moschetti for invaluable collaboration on early stages of this research. We thank participants to the III Health Econometrics Workshop (Siena, December 2012) and two anonymous reviewers for helpful comments and precious advice. Any remaining mistakes are ours. We also thank IMS Health Switzerland for providing data on antibiotic sales.
} 


\section{Introduction}

Prescribing and dispensing of drugs are one of the main aspects of access to primary health care. In most developed countries, the main role of family physicians is to prescribe drugs without direct dispensing. Doctors are not allowed to sell drugs directly to their patients in several OECD countries such as Italy, Germany and Scandinavian countries. Still, direct dispensing is possible in some countries such as Switzerland, where physicians can sell drugs to their patients in most regions (cantons), with some exceptions across the country.

The reason for separating drug prescribing and dispensing is to optimise drug treatment by avoiding a conflict of interest for the prescriber and by ensuring good practice in dispensing (Trap and Hansen, 2003). Lundin (2000) shows that physicians are exposed to moral hazard and the amount and type of drugs prescribed depend on who bears the cost and on the existence of insurance companies that lead physicians to overprescribe. Evidence of moral hazard is reported by Chiappori et al. (1998) and Coulson et al. (1995), respectively, for the demand for home visits and the demand for prescription drugs. Liu et al. (2009) show that profit incentives do affect dispensing physicians, suggesting that physicians act as imperfect agents. Abood (1989) shows that dispensing doctors charge higher retail prices, whereas Rischatsch and Trottmann (2009) indicate that dispensing physicians have a greater probability of prescribing drugs that offer high margin, when compared with non-dispensing physicians. Gilbert (1998) and MortonJones and Pringle (1993) find that dispensing physicians issue more prescriptions per patient and have higher prescribing costs than non-dispensing physicians, respectively. Finally, Trap and Hansen (2002) examine differences in the rationality of the prescription in relation to diagnosis and symptoms and find that dispensing doctors prescribe an antibiotic 2.5 times more frequently than non-dispensing doctors. The authors conclude that dispensing practices may lead to increasing health hazards and bacterial resistance.

Nevertheless, the benefits of separating drug prescribing and dispensing are still unclear. This is because direct dispensing of drugs may increase patient benefits when consumption is characterized by important spillovers, particularly in areas where access to physician services is relatively poor. The purpose of this article is to investigate the role of dispensing physicians in the consumption of health care services (antibiotic treatment) characterized by important consumption externalities. External effects of consumption 
are relevant mainly for anti-infective drugs, and are certainly crucial for antibiotics. Antibiotic drugs are generally used to treat respiratory and gastrointestinal infections which are among the most common infectious diseases acquired in the community. As discussed by Hess et al. (2002), these infections are characterized by a spreading process across regions, i.e. the infection initiates in one region and then spreads across other regions (see Werneck et al. (2002) for an example of the spatial spread of an infection). Consequently, benefits from antibiotic use can extend to other individuals in the community. However, a second type of externality may arise because of endogenous bacterial resistance. This reduces antibiotic effectiveness and increases patient costs (Rudholm, 2002), which in turn enlarges the inefficiency caused by moral hazard.

The effects of consumption externalities are disregarded in all the above studies on the behaviour of dispensing physicians. Hence, the main novelty of the paper as with respect to the existing literature is the inclusion of spatial spillovers in the analysis of antibiotic prescriptions by dispensing physicians. We innovate both from a theoretical and an empirical perspective. We first propose a theoretical model to investigate the behaviour of different types of general practitioners under imperfect information on the nature of patient infections, and prevention and bacterial resistance externalities. We show that antibiotic prescriptions may be higher for dispensing practices, though consumption spillovers may lead to ambiguous results. Then, we propose an empirical exercise which exploits data from small geographic areas in Switzerland where two regimes - prescribing physicians and dispensing physicians - are possible. This provides the ground for a natural experiment.

We consider spatial aspects of antibiotic consumption by means of combined spatial lag and spatial error econometric estimators for panel data (SARAR models). Spatialeconometric estimators in health economics have been recently applied, for instance, by Lachaud (2007), Moscone et al. (2007), and Moscone and Tosetti (2010a, 2010b). These studies underline the importance of taking spatial aspects into account when modelling the utilization of health care services. We are aware of only few empirical studies investigating spillover effects of antibiotic consumption (Filippini et al., 2009a; 2009b; González Ortiz and Masiero, 2013), though without considering dispensing practices. Our empirical analysis indicates that dispensing practices induce higher rates of antibiotics use, after controlling for patient characteristics, epidemiological factors, access to drug treatment, and consumption spillovers. Still, the welfare implications of this result are puzzling. 
The remaining of the article is organized as follows. In Section 2 we sketch the theoretical model and discuss the implications of antibiotic externalities for dispensing and non dispensing practices. Section 3 empirically investigates the impact of dispensing practices on antibiotic use and discusses the results. Section 4 concludes.

\section{Antibiotic treatment in general practice: a theoretical approach}

We investigate the market for antibiotic treatment by extending the classical product differentiation model (Hotelling, 1929) in an infinite-period framework where patients and general practitioners interact under imperfect information on the nature of infections and antibiotic consumption externalities. Nature assigns a health problem (bacterial or viral infection), $i \in\{b, v\}$, to each of the $2 \theta$ individuals uniformly distributed along a unit line at the beginning of each period. Consumers initially observe a symptom but cannot infer the type of infection they suffer from. Each generation of consumers lives for two periods. Therefore, in each period there is a mass of $2 \theta$ consumers: a mass $\theta^{y}$ composed of young consumers and a mass $\theta^{\circ}$ composed of old consumers. The proportion of young consumers entering the market and the proportion of old consumers leaving the market in each period are the same, with $\theta^{y}=\theta^{o}=\theta$. In the first period there is only one generation of consumers, $\theta$, and all of them are young.

In the market there are 2 general practice firms (GP $j$, with $j \in[l, r]$ ) of equal size, located at the two extreme points of the distance. General practitioners can either be allowed to sell drugs directly to their patients or not. All individuals consult a doctor and differ with respect to their location and the type of infection. Doctors make prescriptions based on a diagnosis signal. The accuracy of a GP's prescription is related to the level of diagnostic services provided by the practice $\left(e_{j}\right)$, which is not observable to the patient. Hence, we assume that patient's choice of practice is based upon costly distance.

Patients recover naturally from viral infections after a consultation. However, antibiotics are necessary to recover from bacterial infections. A second consultation is required if the patient suffers from a bacterial infection and an antibiotic is not initially prescribed. Consequently, total demand for consultations of GP $j$ by young patients in each period includes second consultations by patients with a bacterial infection who initially receive a wrong diagnosis. This is summarized by equation (13) in the Appendix. 


\subsection{Prevention and bacterial resistance externalities}

At the beginning of each period, nature assigns a health problem to old patients in the market, like for young patients. However, old patients present a lower probability of infection because they have been exposed to antibiotics prescribed in the previous period. As a consequence, they benefit from the preventive effect of antibiotic use (see also Ellison and Hellerstein, 1999) and do not need to consult a doctor in the second period. We assume that the number of old patients with an infection decreases by a proportion $\phi \in[0,1]$ of the number of young patients (now the old patients) receiving antibiotics in the previous period (from both practices). Antibiotic prescriptions are derived using the demand for consultations by young patients in the Appendix. Consider that only half of the initial number of consultations by young patients from each GP lead eventually to an antibiotic prescription, and some of the young patients receive antibiotics because of wrong diagnosis. Eventually, total demand for consultations for GP $l$ in each period $t$ can be derived by summing up the demand for consultations by young and old patients (see equation (14) in the Appendix). It is worth pointing out that diagnosis effort by GP $j$ in period $t-1$ affects the demand for consultations of both GPs in the following period because of the preventive effect of antibiotic treatment.

A second external effect need to be considered. The use of antibiotics in period $t-1$ reduces the effectiveness of antibiotic treatment in the following period because of bacterial resistance. This raises the cost of treatment and the cost for research and development of new drugs, which represent a negative externality from antibiotic consumption. We capture this effect by assuming that practices face increasing costs $(\rho)$ to cure patients with resistant bacteria. ${ }^{1}$

\subsection{Market equilibrium: the effects of spillovers and dispensing prac- tices}

General practitioners have an objective function that depends upon the benefits and costs of diagnostic services provided in each period. GPs maximize their discounted flow of profits non-cooperatively by choosing the level of diagnostic services and taking their

\footnotetext{
${ }^{1}$ The parameter $\rho$ can also be interpreted as the value of providing good care to patients. Indeed, better diagnostic services in $t-1$ reduce inappropriate antibiotic prescriptions and, consequently, reduce future risks for patients.
} 
competitor's strategies as given. Effort strategies can change over time. ${ }^{2}$ Dispensing physicians differ from other practitioners since they get a markup on costs for drugs sold to the patient. Also, they may incur some costs for keeping drugs on stock. In this sense they are more similar to a pharmacy than to non-dispensing practices. A shortage of stock implies risks if patients are unable to receive the required treatment when needed. On the other hand, large stocks of drugs that have been hoarded increase the risk of getting closer to the expiry date. Unsold drugs may imply some costs for the practice. Physicians' objective and reaction functions and equilibrium conditions are derived in detail in the Appendix (see equations (15)-(16)).

The equilibrium level of diagnostic services can be summarized by the following proposition:

Proposition 1 A symmetric Markov perfect equilibrium in the level of diagnostic services is defined by

$$
e_{l}^{*}=e_{r}^{*}=\frac{\left(\frac{7}{4} \phi-1\right) f+\frac{1}{2} \rho-\left(1-\frac{3}{2} \phi\right) z}{\frac{3 \beta}{4} \phi(f+z)+\frac{4}{\theta \beta} \gamma},
$$

where $\phi$ is the marginal prevention effect of antibiotic use, $f$ is doctor's consultation fee, $\rho$ is the marginal cost of bacterial resistance, $z$ is the price of a dose of antibiotics, $\beta$ is the marginal efficiency of diagnostic services, $\theta$ is doctor's initial number of patients, and $\gamma$ is the marginal cost of diagnostic services.

Equation (1) deserves some comments. Diagnostic services may decrease or increase with the fee for a consultation $(f)$, depending on the magnitude of the prevention effect of antibiotic consumption $(\phi)$. Without positive externalities from antibiotic consumption $(\phi=0)$, the equilibrium level of diagnostic services decreases with the consultation fee. This is because a higher fee increases the marginal gains from consultations. Consequently, there are incentives to reduce diagnosis accuracy, which increases the number of additional consultations. Note also that the negative externality caused by bacterial

\footnotetext{
${ }^{2}$ When choosing diagnosis effort firms not only take into account the effects on their current period profits but also on their demand and costs (bacterial resistance) in the following periods. This dependence needs to be taken into account when solving the model for the equilibrium levels of diagnostic efforts. Profits in period $t$ depends upon diagnostic services in period $t-1$ by both GPs. Also, the value function represented by the flow of all future profits depends on all future levels of diagnosis effort. Consequently, an equilibrium has to ensure that deviations from current period levels of effort in the future are not convenient. We require a perfect equilibrium, i.e. each GP selects the diagnosis effort that maximizes its intertemporal profit given the subsequent strategies of the other GP and itself, whose strategies depend only on the payoff-relevant history (Maskin and Tirole, 1988).
} 
resistance $(\rho)$ increases the equilibrium level of diagnostic services. If the cost of treating patients increases because of resistant bacteria, a higher level of diagnostic services is required to reduce the number of misdiagnosed viral infection and, consequently, the amount of antibiotic prescriptions in previous periods. An increase in diagnosis accuracy lowers the amount of inappropriate prescriptions that contribute to the generation of resistant bacteria. Positive externalities of antibiotic use that decrease the fraction of infected patients in period $t+1$ have a two-fold effect. First, $\phi$ decreases the demand for consultations in period $t+1$. As a consequence, a higher level of diagnostic services is required to reduce the number of antibiotic prescriptions in period $t$ that generate a negative effect on doctor's revenues in period $t+1$ (the numerator of equation (1)). But second, an increase in $\phi$ also decreases the fraction of misdiagnosed infections in period $t+1$, ceteris paribus, which leads to lower prescriptions of antibiotics and reduced gains. To offset this effect, doctors must reduce their level of diagnosis accuracy (the denominator of equation (1)). Since the marginal impact of $\phi$ at the numerator of (1) is larger than the marginal impact at the denominator, the equilibrium level of diagnostic services increases with prevention externalities, i.e. $\partial e^{*} / \partial \phi>0$.

Dispensing practices have an effect on the equilibrium level of diagnosis accuracy through the price of drugs, measured by $z$. Note, however, that this effect depends on the magnitude of positive externalities from antibiotic consumption $(\phi)$, and the efficiency of services provided $(\beta)$. The result is not straightforward. Dispensing practices generally reduce the equilibrium level of diagnostic services as compared to non-dispensing practices, provided that $\phi<2 / 3$. The rationale is that a reduced level of services increases the number of antibiotic prescriptions in period $t$ with relatively low impact on consultations in period $t+1$ and, consequently, the gains from antibiotic sales are higher. This effect is magnified by the reduced incentive to provide accurate diagnosis (at the denominator of (1)) when there are gains from antibiotic sales. However, the result may not hold with strong prevention effects $(\phi>2 / 3)$ and low efficiency of diagnostic services $(\beta \rightarrow 0)$. This is because the marginal impact of antibiotic price at the numerator of $(1)$ becomes positive and prevails over the effect at the denominator.

Using the equilibrium level of diagnostic services defined by (1), we can derive the amount of antibiotic prescriptions per patient. The total number of antibiotic treatments in equilibrium in period $t$ is $2 D_{t}^{A *}=2\left[D_{t}^{*}-\left(\theta-\phi D_{t-1}^{A y *}\right) / 2\right]$. Substituting for $D_{t}^{*}$ and $D_{t-1}^{A y *}$ and dividing by the total number of patients $(2 \theta)$, we get the per capita antibiotic 
use as

$$
a^{*}=\left(1-\frac{\beta}{2} e^{*}\right)\left(1-\phi+\frac{\beta \phi}{2} e^{*}\right)
$$

Whether or not dispensing practices lead to higher levels of antibiotic use compared to non-dispensing practices clearly depends upon the combined effect of financial incentives from antibiotic sales and externalities from antibiotic consumption. With negligible prevention effects $(\phi \rightarrow 0)$ antibiotic prescriptions per capita are higher for dispensing practices as compared to non-dispensing practices. ${ }^{3}$ Conversely, when prevention effects are strong $(\phi \rightarrow 1)$ the result is less straightforward. Note that the first and the second terms may move in opposite directions. Consequently, the hypothesis that dispensing practices increase antibiotic consumption does not follow straightforwardly from our theoretical results and will then be empirically investigated in the following section.

\section{Dispensing practices: an empirical analysis}

\subsection{Institutional background}

Our theoretical framework suggests that the consumption of antibiotics is influenced by factors such as the price of antibiotics and the price of consultations, the incentives attached to direct dispensing of drugs, and positive and negative externalities of antibiotic consumption that exhibit a spatial dimension (see equation (2) above). To investigate further the impact of dispensing practices we propose an empirical approach that exploits panel data from a country - Switzerland - with variation in the regime of dispensing drugs across geographic areas.

Switzerland is a federal state made of 26 cantons (states) with remarkable differences in terms of healthcare organization and policy. Direct dispensing of drugs is not allowed in some cantons (Geneva, Vaud, Balle ville, Ticino and Aargau). In some areas of the other cantons direct dispensing is permitted. Generally, the Cantonal authority allows for direct dispensing to improve access to healthcare services. The decision is related to the structure of the primary care market in different geographic areas, which is relatively stable over time. This decision is not a federal competence and regional regulators independently decide on the organization of the primary care market. Direct dispensing of drugs requires parliament approval, that is a national law has to be passed

\footnotetext{
${ }^{3}$ Note that the second term between brackets of equation (2) tends to 1 , whereas the first term increases since $\partial e^{*} / \partial z>0$ when $\phi \rightarrow 0$.
} 
and is subject to a referendum. Clearly, cultural and historical factors may have played an important role in the evolution of the dispensing regime across the country.

A detailed fee-for-service system with more than 4600 items is applied for the reimbursement of medical services by compulsory private health insurance. A given number of points is assigned to each type of service according to time, complexity and facilities. The cantons apply different values to the basic point, which reflects the heterogeneity in the costs of services across the country.

\subsection{Data and spatial overview}

We have Swiss quarterly data on antibiotic consumption for the year 2002, disaggregated by 240 small geographic areas. Generally, a canton is made up of between 10 and 20 small areas. The population varies between 4,980 and 125,275 inhabitants per area. Each area has at least 4 pharmacies and/or drugstores. Antibiotic consumption is proxied by antibiotic wholesales to all Swiss pharmacies and drugstores provided by IMS Health Switzerland. ${ }^{4}$

Switzerland exhibits relatively low levels of antibiotic consumption compared to neighbouring European countries. The number of defined daily doses per 1000 inhabitants $(D I D)$ in 2002 is 32.05 in France, 24.38 in Italy, 13.76 in Germany, 11.75 in Austria, and only 9.00 in Switzerland (Masiero et al., 2010; Filippini et al., 2006, 2013). Nevertheless, as shown in Figure 1, the country is characterized by high heterogeneity in consumption across small areas. Latin regions (French- and italian-speaking regions) in the Western and Southern part of the country generally exhibit higher levels of antibiotic consumption as compared to German-speaking regions (Central, Northern and Eastern part). Moreover, regions with high levels of consumption (dark coloured) are often adjacent to regions with low levels of consumption, which suggests negative spatial correlation from a visual perspective.

In Figure 2 we illustrate the proportion of dispensing practices in small areas across the country. This proportion is generally lower in Latin regions than in non-Latin regions. Nevertheless, the association between antibiotic consumption depicted in Figure 1 and the presence of dispensing practices does not appear as straightforward as it is probably expected.

\footnotetext{
${ }^{4}$ Detailed data on antibiotic prescriptions and antibiotic use are not available. Consequently, we neglect the possible mismatch between these figures and assume that patient's non-compliance is a negligible factor.
} 


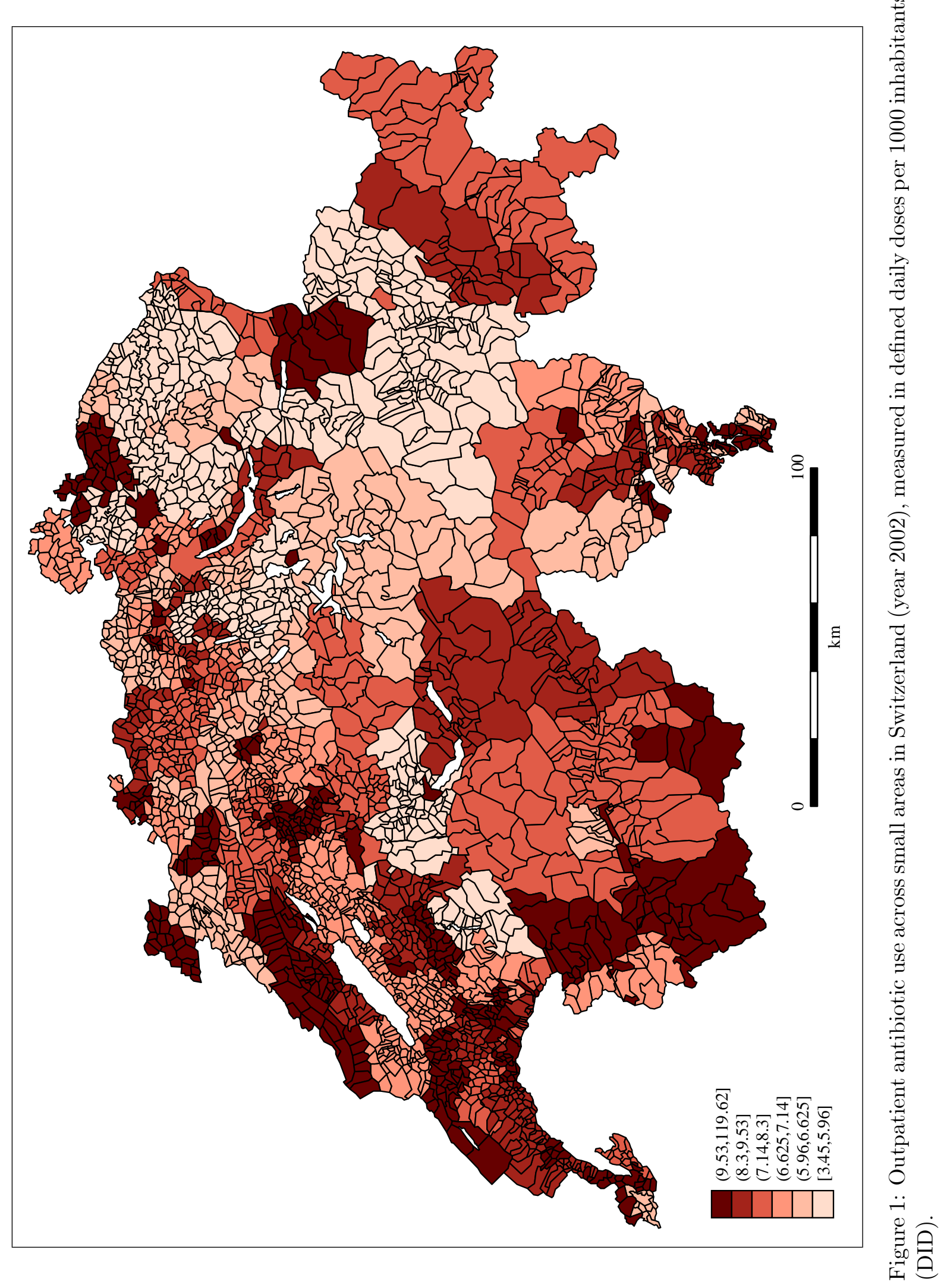




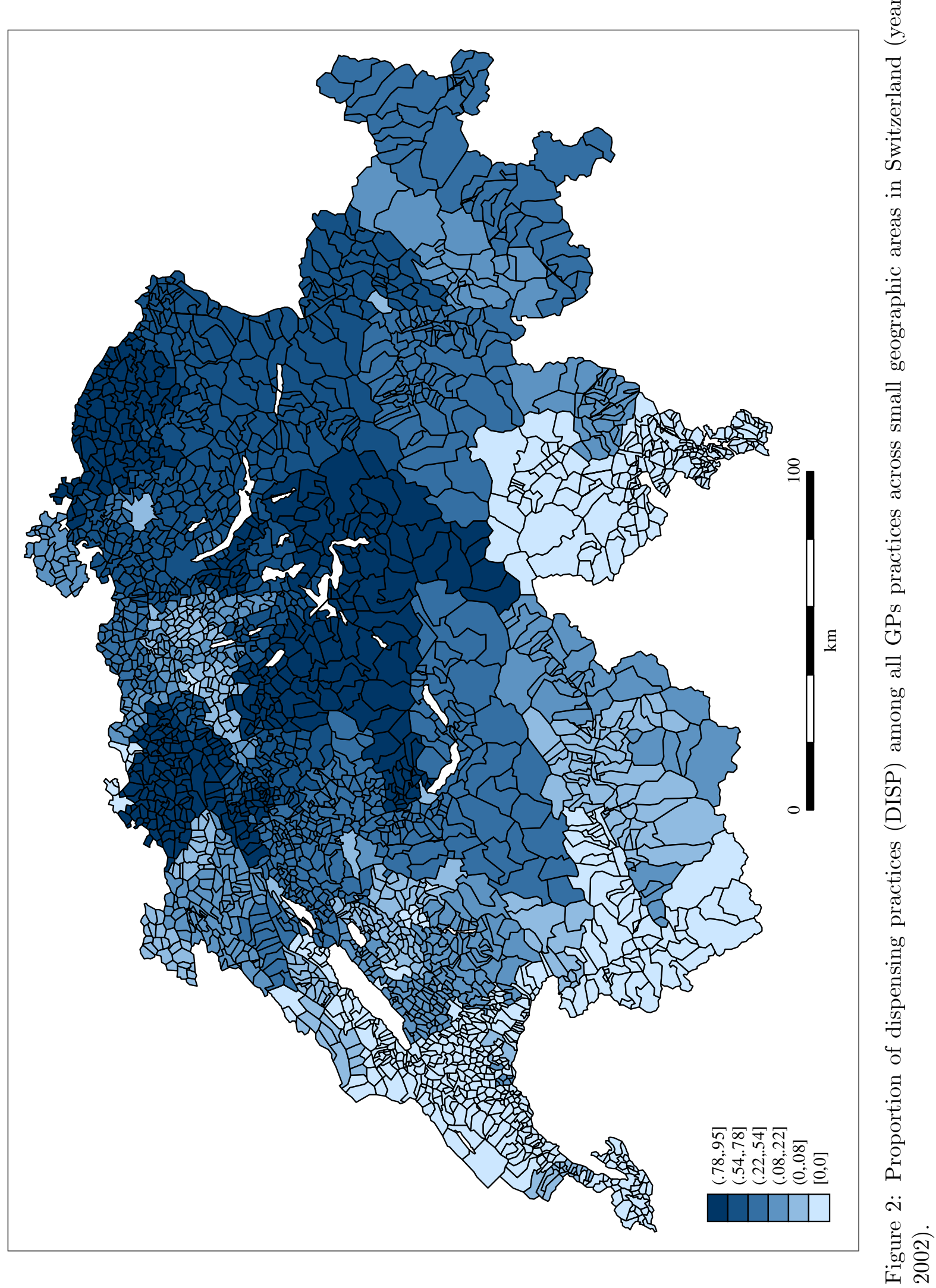




\subsection{Econometric specification}

We adopt a representative consumer approach, namely we specify an econometric model where the dependent variable is the per capita antibiotic consumption in each geographic area:

$$
\ln D I D_{j t}=\beta_{0}+\beta_{P A} \ln P A_{j t}+\beta_{P C} \ln P C_{j t}+\beta_{D} \mathbf{D I S P}_{j t}+\beta_{x} \mathbf{x}_{j t}+\varepsilon_{j t} .
$$

$D I D_{j t}$ is the per capita outpatient antibiotic use in the $j^{\text {th }}$ market area $(j=1, . ., J)$ measured in defined daily doses per 1000 inhabitants. Equation (3) includes the price of a defined daily dose of antibiotics $\left(P A_{j t}\right)$, the price of a standard consultation with a general practitioner $\left(P C_{j t}\right),{ }^{5}$ a vector of our main variables of interest $\left(\mathbf{D I S P}_{j t}\right)$ capturing differences in practice styles and incentives attached to direct dispensing of drugs, and a vector of socioeconomic controls $\left(\mathbf{x}_{j t}\right) . \varepsilon_{j t}$ is the usual error term that will be specified later. We use a log-log functional form and, therefore, the estimated coefficients can be interpreted as elasticities.

In order to capture the impact of dispensing practices we use two approaches. In the first approach, the vector of dispensing variables is based on two dummy variables: $N O D I S P_{j t}$ takes value equal to 1 if there are no dispensing practices in the area, 0 otherwise; $D I S P 50_{j t}$ takes value equal to 1 if the proportion of dispensing practices in the area is greater than $50 \%$. The intermediate case where the proportion of dispensing practices is greater than 0 and lower than $50 \%$ represents our benchmark. ${ }^{6}$ In the second approach, we use a continuous variable $\left(D I S P_{j t}\right)$ for the rate of dispensing practices.

Socioeconomic controls include the density of physicians $\left(D P H Y_{j t}\right)$ and pharmacies $\left(D P H A_{j t}\right)$ in the area, the percentage of population in 5 age ranges $\left(P O P_{1 j t}-P O P_{5 j t}\right)$, and the incidence of bacterial (campylobacter and salmonella) infections $\left(I N F_{j t}\right)$, which is a proxy for the probability of a correct diagnosis in the theoretical model. ${ }^{7}$ Furthermore, the vector of socioeconomic controls includes the average income in the area $\left(Y_{j t}\right)$

\footnotetext{
${ }^{5}$ We use the point value defined by the canton as a proxy for the price of a consultation. Our price is defined at cantonal level for the year 2001.

${ }^{6}$ To investigate the robustness of our estimations, we also consider alternative coding choices. A dummy variable that takes value equal to 1 if there are dispensing practices in the area, and 0 otherwise, is used to overcome possible arbitrariness in setting the threshold to $50 \%$. The results are confirmed.

${ }^{7}$ Campylobacter and salmonella are the leading causes of gastrointestinal infections. Since data are not available at local level, we use information at cantonal level. We do not have more precise information, for instance, on potential need. Diagnosis accuracy improves when the incidence of bacterial infections is high since the probability to prescribe an antibiotic when it is not needed is lower. We use the average incidence of bacterial infections calculated over the years 1999-2001.
} 
and three dummy variables capturing any borderland effect with neighbouring countries $\left(D B O R_{j t}\right)$, whether an area is characterised by Latin (French- and Italian-speaking) or German culture $\left(D L A T_{j t}\right)$, and the presence of at least one hospital in the area $\left(D_{H O S}\right)$. Summary statistics of variables are provided in Table 1.

Per capita antibiotic consumption in equation (3) mirrows per capita antibiotic consumption defined by equation (2), though it does not derive straighforwardly from the theoretical model. Some of the covariates can be interpreted as proxies for the parameters of the theoretical model. The dispensing status $\left(D I S P_{j t}\right)$, for instance, may capture the presence of a markup on drugs sold by dispensing physicians $(z-\eta)$. $P A_{j t}$ is a proxy for the price of antibiotics $(z)$, and $P C_{j t}$ is a proxy for the consultation fee $(f)$. Consumption spillovers in the theoretical model $(\phi$ and $\rho$ ) are captured by the spatial effects of our spatial-econometric specification that will be discussed later in the text.

\begin{tabular}{|c|c|c|c|}
\hline 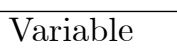 & Description & Mean & Std dev. \\
\hline$\overline{D I D}$ & Defined daily doses per 1000 inhabitants & 11.714 & 13.061 \\
\hline NODISP & $\begin{array}{l}\text { Whether or not there are no dispensing practices } \\
\text { in the area }\end{array}$ & 0.4083 & 0.0159 \\
\hline$D I S P 50$ & $\begin{array}{l}\text { Whether or not there is a majority of dispensing } \\
\text { practices in the area }\end{array}$ & 0.2333 & 0.0137 \\
\hline$D I S P$ & $\%$ of dispensing practices across all practices in the area & 0.2187 & 0.0100 \\
\hline$P A$ & Price of a defined daily dose & 3.7112 & 0.3113 \\
\hline$P C$ & Price of GP consultations & 0.9074 & 0.0526 \\
\hline$Y$ & Income per capita defined in $\mathrm{CHF}$ & 23465 & 6849.4 \\
\hline$P O P_{1}$ & Proportion of $0-14$ in total population & 0.1658 & 0.0243 \\
\hline $\mathrm{POP}_{2}$ & Proportion of $15-25$ in total population & 0.1247 & 0.0173 \\
\hline $\mathrm{POP}_{3}$ & Proportion of 26-59 in total population & 0.4956 & 0.0314 \\
\hline $\mathrm{POP}_{4}$ & Proportion of $60-74$ in total population & 0.1363 & 0.0213 \\
\hline $\mathrm{POP}_{5}$ & Proportion of over 74 in total population & 0.0776 & 0.0190 \\
\hline$I N F$ & $\begin{array}{l}\text { Incidence of common gastrointestinal infections } \\
\text { (salmonella and campylobacter) in } 100000 \text { inhabitants }\end{array}$ & 114.69 & 22.580 \\
\hline$D P H Y$ & Density of physicians for 100000 inhabitants & 565.21 & 1052.5 \\
\hline DPHA & Density of pharmacies for 100000 inhabitants & 35.098 & 39.112 \\
\hline$D B O R$ & Whether or not the area borders other countries & 0.125 & 0.0107 \\
\hline$D L A T$ & $\begin{array}{l}\text { Whether an area has a Latin (French and Italian) } \\
\text { or a German culture }\end{array}$ & 0.4375 & 0.0160 \\
\hline DHOS & Whether or not there is at least one hospital in the area & 0.7417 & 0.0141 \\
\hline
\end{tabular}

Table 1: Variables notation and summary statistics.

A correct econometric approach to the estimation of equation (3) has to deal with three main issues: the possible endogeneity of price, ${ }^{8}$ the presence of unobserved het-

\footnotetext{
${ }^{8}$ Although both the Wu-Hausman F-test and the Durbin-Wu-Hausman $\chi^{2}$-test do not clearly reject the null hypothesis of price exogeneity, we deal with this potential endogeneity problem by treating the price
} 
erogeneity variables, such as infection variables, and the possible spatial correlation of antibiotic consumption across regions. To address unobserved heterogeneity and spatial correlation, we follow a two-step approach. We first estimate classical non-spatial econometric models for panel data. Later, we apply spatial panel data models where the effects of antibiotic consumption externalities are captured by means of a combined spatial lag and spatial error econometric approach. Since data at our disposal cover a relatively short period of time and the estimation of a dynamic model with spatial econometric methods is not straightforward, our approach focuses on static (spatial-dynamic) models rather than time-dynamic models. ${ }^{9}$

To account for unobserved heterogeneity, we can specify our model (3) with either geographic area-specific fixed effects (FE) or with geographic area-specific random effects (RE). ${ }^{10}$ However, since most of our explanatory variables, including dispensing variables, do not exhibit within variation, we prefer a $\mathrm{RE}$ estimator. ${ }^{11}$ Indeed, none of the regions changed the dispensing regime during the period of the analysis. Hence, a FE model is not suitable. For comparison purposes and to check the robustness of the results, we also use the between (BE) estimator. In this case, the estimation of model (3) using quarterly data and cross-sectional data is equivalent. Generally, the results are very similar to those of the RE model.

As for spatial aspects, we expect that regional antibiotic consumption is affected by individuals' and physicians' attitudes towards antibiotics as well as the presence of infectious diseases in adjacent regions. Spatial effects can be taken into account by means of adequate spatial econometrics estimators. ${ }^{12}$ To incorporate spatial effects we can follow two approaches: the spatial lag model and the spatial error model or, as proposed by

as an endogenous variable and instrument it with the lagged value of price and the exogenous regressors. The price of each antibiotic product does not vary across geographic areas in Switzerland. However, the average price for a daily dose of antibiotics differs because geographic regions vary in the consumption mix of different antibiotic categories. Consequently, the price for a daily dose can be endogenous.

${ }^{9}$ For a time-dynamic approach to antibiotic consumption we refer the reader to a recent paper by Filippini and Masiero (2012) which uses Italian data.

${ }^{10}$ For a detailed presentation of econometric methods for panel data see Baltagi (2008) and Greene (2012).

${ }^{11}$ We test the hypothesis that the explanatory variables and the individual-specific error terms are uncorrelated using the Hausman test. The result of the test shows that differences in coefficients between the RE and the FE models are not systematic, thus implying that the RE model can be preferred.

\footnotetext{
${ }^{12}$ For a general introduction to spatial econometrics see Anselin (1988, 2001). For applications of spatial econometric methods in health economics see, for instance, Moscone and Knapp (2005) and Moscone et al. (2007). For applications to the economics of antibiotics, see Filippini et al. (2009a, 2009b) and González Ortiz and Masiero (2013).
} 
Kapoor et al. (2007), an econometric model that combine these two models. We adopt the RE spatial error and spatial lag model. ${ }^{13}$ As suggested by Moscone and Knapp (2005), the spatial error model is relevant when the distribution of residuals in different regions displays spatial correlation. Residual may be spatially correlated if aggregated shocks hit regional health authorities or there are unobservable risk factors concentrated across the areas. In our case, this effect may be due, for instance, to an infectious disease breakdown spreading across the country or unobservable bacterial resistance.

We expect the spatial error coefficient to be positive, because infectious diseases or unobservable bacterial resistance breakdown in the neighbourhood of area $j$ will determine an increase of antibiotic consumption in the area. On the other side, we expect the spatial lag coefficient to be negative because of the presence of spatial spillovers. A general increase of antibiotic consumption in a neighborhood area decreases the need to consume antibiotics because the probability of contagion decreases. The spatial lag coefficient can be interpreted as a proxy for the infection prevention spillover in the theoretical model $(\phi)$. This indicates that infection prevention spillovers reduce antibiotic consumption since doctors have the incentive to make more accurate diagnosis. Furthermore, the spatial error coefficient may represent a proxy for resistance externality in the theoretical model $(\rho)$. The theoretical model predicts that antibiotic consumption is higher when bacterial resistance is unknown to the doctor, i.e. $\rho=0$, since the costs of reduced antibiotic effectiveness are ignored. This would suggest a positive effect of the (unobservable) spatial error component. Conversely, if the effect of bacterial resistance is internalized, i.e $\rho>0$, then physicians increase diagnosis accuracy, which in turn reduces antibiotic consumption. In this case, the effect of bacterial resistance will not be captured by the (unobservable) spatial error component, but rather by the (deterministic) spatial lag coefficient.

The econometric specification of the RE model for panel data with $J$ cross-sectional units observed over $T$ time periods including spatial effects, also referred as SARAR

\footnotetext{
${ }^{13}$ In order to test the presence of spatial autocorrelation we consider several preliminary tests. The Moran's I statistic as described by Kelejian and Prucha (2001) is applied to check for spatial correlation in the residuals. We also employ the testing procedure described in Baltagi et al. (2007). Both tests reject the null hypothesis of no spatial correlation in the residuals at $1 \%$ significance level (p-value 0.01 ). In order to test for spatial correlation in the dependent variable, we apply the test described in Baltagi and Long (2008). The test rejects the null hypothesis of no spatial correlation in the dependent variable at less than $5 \%$ significance level (p-value $=0.018)$.
} 
model and proposed by Kapoor et al. (2007), is defined as

$$
\begin{aligned}
D I D & =\lambda \cdot\left(W \otimes I_{T}\right) \cdot D I D+X \cdot \beta+u \\
u & =\rho \cdot\left(M \otimes I_{T}\right) \cdot u+\varepsilon \\
\varepsilon & =\mu \otimes e_{T}+v
\end{aligned}
$$

where $D I D$ is a $J x 1$ vector of observations on antibiotic consumption per capita; $X$ is the $J x Q$ matrix of explanatory variables; $\beta$ is the vector of regression parameters; $W$ and $M$ are the matrix of spatial weights; $u$ is a vector of spatially lagged residuals; $\mu$ is a vector of individual effects and $v$ is a vector of i.i.d. residuals; finally $\lambda$ and $\gamma$ are the spatial lag and spatial error respectively.

We use identical spatial weight matrices, both for spatial correlation in the dependent variable and spatial correlation in the residuals, which are defined by a contiguity matrix with positive entries if two regions are adjacent to each other, and zero otherwise. The matrix is normalized such that all the rows sum up to one. An illustration of the spatial weights is given by Figure 3 .

Concerning $\varepsilon$, following assumptions are made:

$$
\begin{aligned}
\varepsilon & =\mu \otimes e_{T}+v \\
E(\mu) & =0 \\
E\left(\mu \cdot \mu^{\prime}\right) & =\sigma_{\mu}^{2} \cdot I_{J} \\
E(v) & =0 \\
E\left(v \cdot v^{\prime}\right) & =\sigma_{v}^{2} \cdot I_{J T} \\
E\left(v^{\prime} \cdot\left(\mu \otimes e_{T}\right)\right) & =0
\end{aligned}
$$

where $\mu$ is a (Jx1) vector of individual (random) effects with zero mean, zero covariance and variance $\sigma_{\mu}^{2}$. Further, $\mu_{j}$ and $v_{j t}$ are i.i.d. with finite fourth moments. It is assumed that the matrices $I_{J}-\lambda W$ and $I_{J}-\rho M$ are invertible (non-singular) and that $\lambda, \rho$ are bounded in absolute value.

As expected the Wu-Hausman F-test rejects the null hypothesis of exogeneity of the spatially lagged dependent variable at less than $0.1 \%$ significance level. To deal with endogeneity, we also treat the spatially lagged dependent variable as endogenous, together with price, and instrument it with the spatially lagged exogenous regressors and lagged price. Note that we can only use three quarters for our estimations since the lagged price 


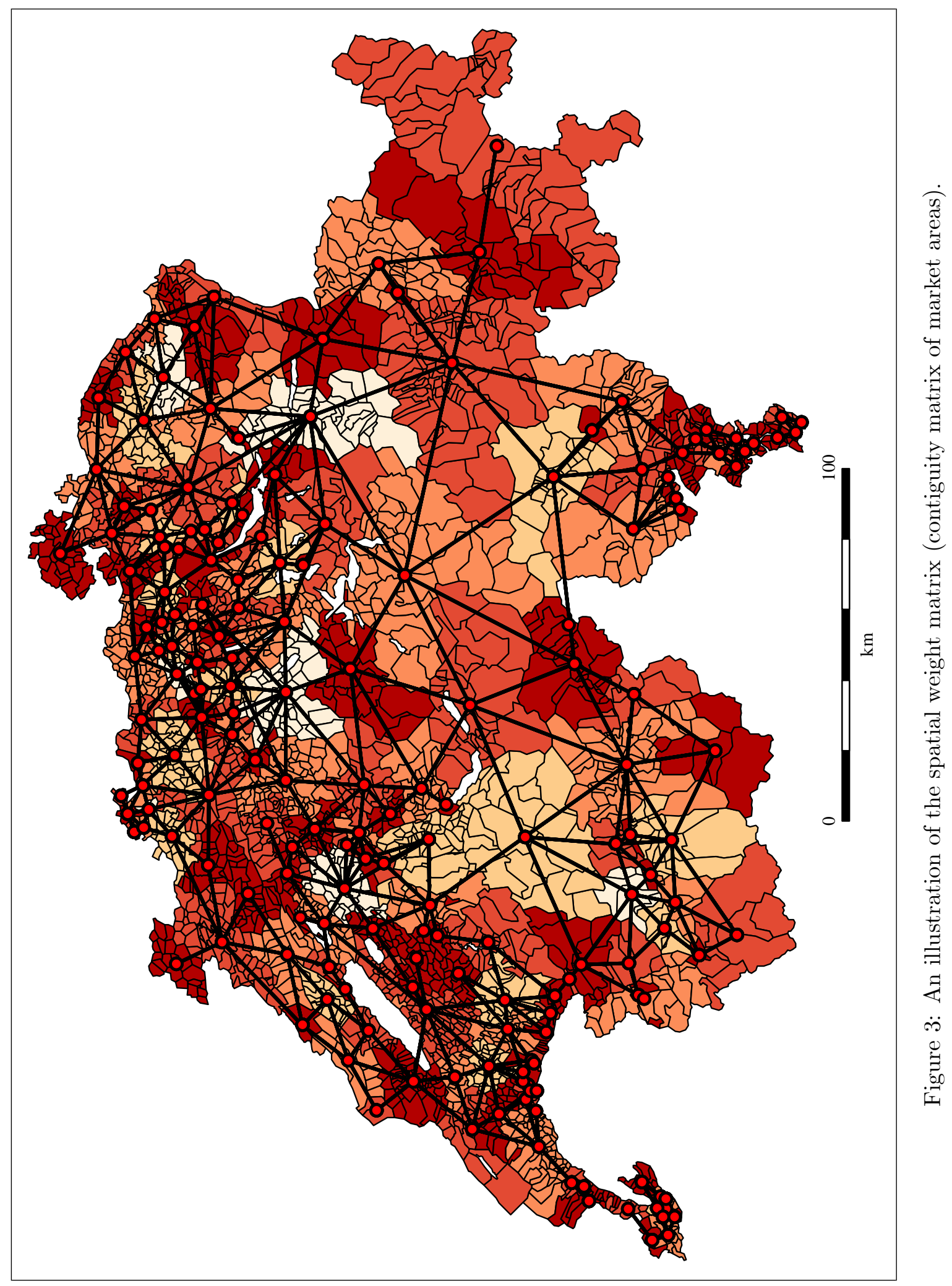


is included as an instrument. First-stage regressions on the instruments yield significant joint F-tests. Moreover, the p-value of the Sargan-test statistics does not reject the null hypothesis and concludes that the overidentifying restriction is valid.

For the estimation of the models we follow the approach suggested by Kapoor et al. (2007), and use a generalized moment estimator. Moreover, since current STATA commands do not combine the estimation of spatial lag and spatial error models, we develop additional STATA codes. ${ }^{14}$

\subsection{Estimation results}

The results of the estimation of equation (3) using the RE model without spatial error and spatial lag effects (RE2SLS) are reported in Table 2. Models with spatial effects (SRE2SLS) are summarized in Table 3. Both tables include the estimation results of two model specifications defined by different measures of dispensing practices: two dummy variables (NODISP and DISP50) and a continuous dispensing variable $(D I S P)$.

Generally, the value of the parameters and the number of significant parameters in spatial models are relatively close to those reported for the non-spatial models. When spatial effects are taken into account, the estimated elasticity of income increases. Further, in both spatial models the age structure of the population has a lower impact on the per capita antibiotic sales than in models without spatial effects. The estimated impact of bacterial infections is positive as expected, but poorly significant. Finally, the density of physicians and pharmacies are positively and significantly associated with local per capita antibiotic use.

The values of price elasticity of antibiotics obtained in the BE model are close to the estimates of Baye et al. (1997), who find negative compensated (-0.785) and uncompensated (-0.916) own-price effects for anti-infectives. Ellison et al. (1997) calculate price elasticities irrespective of drug (cephalosporins) expenditure using US wholesales data from 1985 to 1991 . Their estimates range between -0.38 and -4.34 . Our estimated price elasticities range between 0.14 (not significant in non-spatial models) to -0.55 (highly significant in spatial models). The coefficient of price of medical consultations is not significant. Although expensive consultations imply higher diagnosis effort, which may reduce inappropriate prescriptions of antibiotics, this hypothesis is not confirmed

\footnotetext{
${ }^{14}$ The main components of these codes are borrowed from Kapoor's notes. The do- and ado-files are available upon request to the authors and may require some preliminary instructions since their format differ from official STATA ado-files.
} 
Random-effects IV regressions

Dispensing dummies Continous dispensing variable

\begin{tabular}{lrrrrrr}
\hline Covariates & Coefficients & St. Err. & p-value & Coefficients & St. Err. & p-value \\
\hline Constant & -2.198744 & 1.427119 & 0.123 & -3.024184 & 1.437677 & 0.035 \\
NODISP & -0.0441112 & 0.0614449 & 0.473 & & & \\
DISP50 & 0.2993839 & 0.0602715 & 0.000 & & & \\
DISP & & & & 0.5856185 & 0.0938454 & 0.000 \\
PA & 0.1435792 & 0.7619403 & 0.851 & 0.192503 & 0.817172 & 0.814 \\
PC & 0.2545297 & 0.4248651 & 0.549 & 0.3310219 & 0.4261601 & 0.437 \\
Y & 0.1341392 & 0.1086522 & 0.217 & 0.1494742 & 0.1065245 & 0.161 \\
POP $_{1}$ & 0.7770858 & 0.2902369 & 0.007 & 0.707528 & 0.2854014 & 0.013 \\
POP $_{2}$ & -0.3992381 & 0.2628232 & 0.129 & -0.4388904 & 0.258685 & 0.090 \\
POP $_{4}$ & -0.0832129 & 0.2108611 & 0.693 & -0.1966698 & 0.2121132 & 0.354 \\
POP & -0.2448346 & 0.1039692 & 0.019 & -0.2192098 & 0.1017727 & 0.031 \\
INF & 0.0146288 & 0.0420017 & 0.728 & 0.0329257 & 0.0410286 & 0.422 \\
DPHY & 0.1271244 & 0.0340157 & 0.000 & 0.1181553 & 0.0334417 & 0.000 \\
DPHA & 0.6092891 & 0.0513577 & 0.000 & 0.6456287 & 0.0515961 & 0.000 \\
DBOR & -0.0001904 & 0.0583645 & 0.997 & 0.0076729 & 0.0560429 & 0.891 \\
DLAT & -0.0618509 & 0.0921805 & 0.502 & -0.034946 & 0.0872025 & 0.689 \\
DHOSP & -0.0006248 & 0.0560705 & 0.991 & -0.0011009 & 0.0554195 & 0.984 \\
dt $_{2}$ & -0.1982564 & 0.0143699 & 0.000 & -0.1974589 & 0.015179 & 0.000 \\
$\mathrm{dt}_{3}$ & -0.1824587 & 0.0149339 & 0.000 & -0.1816195 & 0.0157927 & 0.000 \\
\hline$\sigma_{\kappa}$ & 0.25347992 & & & 0.24544706 & & \\
$\sigma_{\epsilon}$ & 0.07584716 & & & 0.07584716 & & \\
$\sigma^{2}$ due to $\mu_{i}$ & 0.91782296 & & & 0.91283258 & & \\
\hline Number of obs. & & 720 & & & 720 & \\
Number of groups & & 240 & & & 0.6545 & \\
$\mathrm{R}^{2}$ within & & 0.6599 & & & 0.7497 & \\
$\mathrm{R}^{2}$ between & & 0.7369 & & & 0.7452 & \\
$\mathrm{R}^{2}$ overall & & 0.7333 & & & \\
\hline
\end{tabular}

Notes: The instruments used in the random-effects IV regressions (RE2SLS) are the lagged variable of price $\left(P A_{t-1}\right), Y_{t}, P O P_{1 t}, P O P_{2 t}, P O P_{4 t}, P O P_{5 t}, I N F_{t}, D P H Y_{t}, D P H A_{t}, P C_{t}, D B O R_{t}, D L A T_{t}, D H O S P_{t}$, $N O D I S P_{t}, D I S P 50_{t}\left(D I S P_{t}\right.$ in the continous variable regression), $d t_{2}$, and $d t_{3}$. First-stage regressions on the instruments yield significant joint F-tests.

Table 2: Parameter estimates of random-effects IV regressions (RE2SLS). 
by our results.

The impact of direct dispensing of drugs is of major interest to us. The results reported by spatial models (Table 3) confirm the results of models without spatial effects (Table 2). These indicate that the proportion of practices without dispensing (NODISP) has a negative effect on antibiotic sales in both models, although the coefficient is not significant. Consequently, we cannot reject the hypothesis that areas without dispensing practices and areas with a relatively small proportion of dispensing practices (below $50 \%$ ) exhibit similar levels of antibiotic consumption per capita. However, when the proportion of dispensing practices is relatively high (more than 50\%), the effect on antibiotic consumption is positive and significant. The estimated coefficients suggest that in market areas where the proportion of dispensing practices is relatively high, antibiotic consumption is 1.30 to 1.37 times higher than in the other market areas, respectively for non-spatial and spatial model specifications. This effect is confirmed by the results obtained using a continuous variable representing the share of dispensing practices in each market area. ${ }^{15}$ The value of the estimated elasticity varies between 0.58 and 0.68 and is highly significant. This suggests that a one percent increase in the proportion of dispensing practices will increase per capita antibiotic consumption by $0.58 \%$ to $0.68 \% .{ }^{16}$ Clearly, the association between antibiotic consumption and the dispensing regime could be due to several reasons. For instance, once the dispensing status has been granted, it is probably hard to remove the right to dispense, particularly in high revenue drug regions and because of strong doctors' ability to lobby. Also, drug consumption and dispensing status may both be determined by cultural and historical factors.

The estimates of the spatial error coefficient $(\rho)$ and the estimates of the spatial lag coefficient $(\lambda)$ are statistically significant and carry the expected sign. ${ }^{17}$ The positive spa-

\footnotetext{
${ }^{15}$ To check whether there is an interaction between GPs market power and the integration of prescribing and dispensing, we test interaction terms between the density of physicians and dispensing variables. These are always insignificant, both in spatial and non-spatial regressions. This is somehow expected since the density of physicians and dispensing covariates are highly significant. Most of the variation is then captured by these variables included separately, and little is left for their interaction. Also, the interaction between the price of antibiotics or the price of physician consultations with the dispensing regime does not affect our main results and the coefficient is not significant.

${ }^{16} \mathrm{We}$ also run separate regressions with the density of the population as an additional regressor. This allows to better captures the level of urbanization of the areas and, consequently, can be used as a proxy for travelling distances. The variable is never significant, nor does it change the results of the other covariates significantly. We are then confident that our estimates of the effect of dispensing practices on antibiotic consumption is quite robust to possible misspecification related to access to medical treatment.

${ }^{17}$ To investigate the robustness of these results we also estimate spatial lag models and a spatial error models separately. The estimates confirm the results reported in Table 3.
} 
tial error coefficient may suggest that unobservable aspects, such as bacterial resistance, or random shocks, such as a disease outbreak in surrounding areas, will determine an increase of antibiotic consumption in area $i$. Other more deterministic spatial spillovers are captured by the negative spatial lag coefficient. In this case an increase in the consumption of antibiotics in neighborhood areas decreases antibiotic consumption in area $i$. This may indicate that the probability of contagions decreases due to the preventive effect of antibiotic consumption, or that physicians are aware of the adverse effects of endogenous bacterial resistance and internalize this information in their prescribing decisions. Overall, these results confirm the relevance of spatial econometric models in the analysis of antibiotic consumption and the effect of dispensing practices.

\section{Conclusions}

Prescribing and dispensing of drugs are important aspects of access to primary health care. In most developed countries, these aspects are kept separate and doctors are not allowed to sell drugs directly to their patients. The separation of prescribing and dispensing has proved to be effective in reducing drug expenditure, for instance in Taiwan (Chou et al., 2003). However, this separation may be costly in terms of limited access to drug treatment and low levels of infection prevention. In Switzerland, physicians are allowed to sell drugs directly to their patients in most cantons, with some exceptions across the country.

In this paper, we first extended the classical spatial model to investigate the impact of dispensing practices on the consumption of antibiotics under positive (infection prevention) and negative (bacterial resistance) consumption externalities. We showed that the interaction between consumption externalities and incentives to dispensing practices may reduce diagnosis accuracy and, consequently, increase the likelihood of antibiotic prescriptions. The rationale behind a higher consumption of antibiotics under a dispensing regime may be that dispensing practices are more exposed to moral hazard. Nevertheless, this effect may be mitigated by the positive externality of infection prevention and control.

We then examined the effects of dispensing practices empirically using data on antibiotic consumption in small geographic areas from a country (Switzerland) with two regimes for general practitioners - with and without direct dispensing of drugs. The approach relies on spatial-econometric estimators for panel data, which take spatial aspects 


\begin{tabular}{|c|c|c|c|c|c|c|}
\hline \multirow{3}{*}{ Covariates } & \multicolumn{6}{|c|}{ Spatial random-effects IV regressions } \\
\hline & \multicolumn{3}{|c|}{ Dispensing dummies } & \multicolumn{3}{|c|}{ Continous dispensing variable } \\
\hline & Coefficients & St. Err. & $\mathrm{p}$-value & Coefficients & St. Err. & p-value \\
\hline Constant & -0.5600248 & 0.7059426 & 0.428 & -0.931256 & 0.6927078 & 0.179 \\
\hline NODISP & 0.0075422 & 0.0545024 & 0.890 & & & \\
\hline DISP50 & 0.3738889 & 0.0632064 & 0.000 & & & \\
\hline DISP & & & & 0.6853876 & 0.0992924 & 0.000 \\
\hline PA & -0.5476143 & 0.3067118 & 0.074 & -0.4935378 & 0.3062494 & 0.107 \\
\hline PC & 0.0614923 & 0.4785733 & 0.898 & 0.1189752 & 0.4670196 & 0.799 \\
\hline Y & 0.2506859 & 0.1172455 & 0.033 & 0.2670415 & 0.1139665 & 0.019 \\
\hline $\mathrm{POP}_{1}$ & 0.4642093 & 0.267977 & 0.083 & 0.4615374 & 0.2614212 & 0.077 \\
\hline $\mathrm{POP}_{2}$ & -0.349267 & 0.2318164 & 0.132 & -0.4088315 & 0.2255809 & 0.070 \\
\hline $\mathrm{POP}_{4}$ & -0.1101778 & 0.1879261 & 0.558 & -0.1769792 & 0.1842804 & 0.337 \\
\hline $\mathrm{POP}_{5}$ & -0.2025597 & 0.0939734 & 0.031 & -0.1504447 & 0.0928847 & 0.105 \\
\hline INF & 0.0072868 & 0.0549224 & 0.894 & 0.0310215 & 0.0539316 & 0.565 \\
\hline DPHY & 0.0788513 & 0.027162 & 0.004 & 0.0768944 & 0.0264956 & 0.004 \\
\hline DPHA & 0.6536462 & 0.0468989 & 0.000 & 0.6916768 & 0.0469933 & 0.000 \\
\hline DBOR & 0.0275946 & 0.0605708 & 0.649 & 0.0554975 & 0.0593344 & 0.350 \\
\hline DLAT & 0.0678903 & 0.0898894 & 0.450 & 0.1175204 & 0.0818143 & 0.151 \\
\hline DHOSP & 0.0100526 & 0.0462533 & 0.828 & 0.0089593 & 0.0451583 & 0.843 \\
\hline $\mathrm{dt}_{2}$ & -0.1355012 & 0.0108294 & 0.000 & -0.1326363 & 0.0107027 & 0.000 \\
\hline $\mathrm{dt}_{3}$ & -0.1270158 & 0.0104178 & 0.000 & -0.1242904 & 0.0103106 & 0.000 \\
\hline$\lambda$ & -0.3537783 & 0.0891222 & 0.000 & -0.3323822 & 0.0871533 & 0.000 \\
\hline$\rho$ & 0.5346576 & 0.0534699 & 0.063 & 0.5346576 & 0.0534699 & 0.063 \\
\hline$\sigma_{\kappa}$ & 0.23122444 & & & 0.22573567 & & \\
\hline$\sigma_{\epsilon}$ & 0.070791 & & & 0.070791 & & \\
\hline$\sigma^{2}$ due to $\mu_{i}$ & 0.91430063 & & & 0.91046009 & & \\
\hline Number of obs. & & 720 & & & 720 & \\
\hline Number of groups & & 240 & & & 240 & \\
\hline $\mathrm{R}^{2}$ within & & 0.4055 & & & 0.4076 & \\
\hline $\mathrm{R}^{2}$ between & & 0.7921 & & & 0.8005 & \\
\hline $\mathrm{R}^{2}$ overall & & 0.7839 & & & 0.7923 & \\
\hline
\end{tabular}

Notes: The instruments used in the spatial random-effects IV regressions (SRE2SLS) are the lagged variable of price $\left(P A_{t-1}\right), Y_{t}, P O P_{1 t}, P O P_{2 t}, P O P_{4 t}, P O P_{5 t}, I N F_{t}, D P H Y_{t}, D P H A_{t}, P C_{t}, D B O R_{t}, D L A T_{t}$, $D H O S P_{t}, N O D I S P_{t}, D I S P 50_{t}$ (DISPt in the continous variable regression), $d t_{2}, d t_{3}$, and their spatial lags. First-stage regressions on the instruments yield significant joint F-tests. Moreover, the p-value of the Sargan-test statistics does not reject the null hypothesis and concludes that the overidentifying restriction is valid.

Table 3: Parameter estimates of spatial random-effects IV regressions (SRE2SLS). 
of antibiotic consumption (both spatial lag and spatial error effects) into account. Findings indicate that dispensing practices are associated to higher rates of antibiotic use, after controlling for spatial consumption externalities. Nevertheless, the social implications of this result are puzzling. Evidence of important spatial spillovers, some of which are unobservable, suggests that socially optimal levels of antibiotic consumption cannot be easily defined. It has been shown that Switzerland exhibits relatively low levels of antibiotic consumption as compared to other European countries. Consequently, whether a regime of direct dispensing lead to overuse of antibiotics is unclear. This may raise public concern over a correct evaluation of all benefits and costs of direct dispensing of antibiotic treatment and foster further research in the area. 


\section{References}

Abood, R.R., 1989. Physician dispensing: issues of law, legislation and social policy. American Journal of Law \& Medicine 14, 4, 307-52.

Anselin, L., 1988. Spatial econometrics: methods and models, Kluwer, Dordrecht, The Netherlands.

Anselin, L., 2001. Spatial econometrics. In: Baltagi, B.H. (Ed.), A companion to theoretical econometrics. Basil Blackwell, Oxford, pp. 310-330.

Baltagi, B.H., 2008. Econometric analysis of panel data, 4th edn, John Wiley \& Sons, Chichester, England.

Baltagi, B.H., Song, S.H., Jung, B.C., Koh, W., 2007. Testing for serial correlation, spatial autocorrelation and random effects using panel data. Journal of Econometrics, $140,1,5-51$.

Baltagi, B.H., Long, L., 2008. Testing for random effects and spatial lag dependence in panel data models. Center for Policy Research Working Paper No 102.

Baye, M.R., Maness, R., Wiggins, S.N., 1997. Demand systems and the true subindex of the cost of living for pharmaceuticals. Applied Economics 29, 1179-1189.

Chiappori, P.-A., Durand, F., Geoffard, P.-Y., 1998. Moral hazard and the demand for physician services: First lessons from a French natural experiment. European Economic Review 42, 3-5, 499-511.

Chou, Y., Yip, W.C., Lee, C.-H., Huang, N., Sun, Y.-P., and Chang, H.-J., 2003. Impact of separating drug prescribing and dispensing on provider behaviour: Taiwan's experience. Health Policy and Planning 18, 3, 316-329.

Coulson, N.E., Terza, J.V., Neslusan C.A., Stuart, B.C., 1995. Estimating the moralhazard effect of supplemental medical insurance in the demand for prescription drugs by the elderly. The American Economic Review 85, 2, 122-126.

Ellison, S.F., Cockburn, I., Griliches, Z., and Hausman, J., 1997. Characteristics of demand for pharmaceutical products: an examination of four cephalosporins. RAND Journal of Economics 28, 426-446.

Ellison, S.F., Hellerstein, J.K., 1999. The economics of antibiotics: an exploratory study. In: Triplett, J.E. (Ed.), Measuring the prices of medical treatments. Brookings Institution Press, Washington DC, pp. 118-43.

Filippini M., Masiero, G., Moschetti, K. 2006. Socioeconomic determinants of regional 
differences in outpatient antibiotic consumption: Evidence from Switzerland. Health Policy, 78, 77-92.

Filippini, M., Masiero, G., Moschetti, K., 2009a. Small area variations and welfare loss in the use of outpatient antibiotics. Health Economics, Policy and Law 4, 55-77.

Filippini, M., Masiero, G., Moschetti, K., 2009b. Regional consumption of antibiotics: a demand system approach. Economic Modelling 26, 1389-1397.

Filippini, M., Masiero, G., 2012. An empirical analysis of habit and addiction to antibiotics. Empirical Economics, 42, 471-486.

Filippini, M., González Ortiz, L.G., Masiero, G., 2013. Assessing the impact of national antibiotic campaigns in Europe. European Journal of Health Economics, 14, 587-599.

Gilbert, L., 1998. Dispensing doctors and prescribing pharmacists: A South African perspective. Social Science and Medicine, 46, 1, 83-95.

González Ortiz, L.G., Masiero, G., 2013. Disentangling spillover effects of antibiotic consumption: a spatial panel approach. Applied Economics 45, 1041-1054.

Greene W., 2012. Econometric analysis. 7th edn. Upper Saddle River NJ: Pearson Prentice Hall.

Hess, G.R., Randolph, S.E., Arneberg, P., Chemini, C., Furlanello, C., Harwood, J., Roberts, M., and Swinton, J., 2002. Spatial aspects of disease dynamics. In: Hudson, P.J. et al. (Eds.), The ecology of wildlife diseases. Oxford University Press, New York, $102-118$.

Hotelling, H., 1929. Stability in competition. Economic Journal, 39 (January), 41-57.

Kapoor, M., Kelejian, H.H., Prucha, I.R., 2007. Panel data models with spatially correlated error components. Journal of Econometrics 140, 1, 97-130.

Kelejian, H., Prucha, I.R., 2001. On the asymptotic distribution of the Moran I test statistic with applications. Journal of Econometrics, 104, 2, 219-257.

Lachaud, J.-P., 2007. HIV prevalence and poverty in Africa: Micro- and macro-econometric evidences applied to Burkina Faso. Journal of Health Economics 26, 483-504.

Liu, Y.-M., Yang, Y.-H.K., Hsieh, C.-R., 2009. Financial incentives and physicians' prescription decisions on the choice between brand-name and generic drugs: Evidence from Taiwan. Journal of Health Economics 28, 341-349.

Lundin, D., 2000. Moral hazard in physician prescription behavior. Journal of Health Economics, 19, 639-662.

Masiero, G., Filippini, M., Ferech, M., Goossens, H., 2010. Socioeconomic determinants 
of outpatient antibiotic use in Europe. International Journal of Public Health, 55, 469478.

Maskin, E., Tirole, J., 1988. A Theory of Dynamic Oligopoly, I: Overview and Quantity Competition with Large Fixed Costs. Econometrica, 56, 549-569.

Morton-Jones, T.J., Pringle, M.A., 1993. Prescribing costs in dispensing practices. British Medical Journal 306, 6887, 1244-1246.

Moscone, F., Knapp, M., 2005. Exploring the spatial pattern of mental health expenditure. Journal of Mental Health Policy and Economics 8, 205-217.

Moscone, F., Knapp, M., Tosetti, E., 2007. Mental health expenditure in England: A spatial panel approach. Journal of Health Economics 26, 842-864.

Moscone, F., Tosetti, E., 2010a. Health expenditure and income in the United States. Health Economics 19, 12, 1385-1403.

Moscone, F., Tosetti, E., 2010b. Testing for error cross section independence with an application to US health expenditure. Regional Science and Urban Economics 40, 283291.

Rischatsch, M., Trottmann, M., 2009. Physician dispensing and the choice between generic and brand-name drugs - Do margins affect choice?. Working Paper No. 0911, University of Zurich.

Rudholm, N., 2002. Economic implications of antibiotic resistance in a global economy. Journal of Health Economics 21, 1071-1083.

Trap, B., Hansen, E.H., 2002. Cotrimoxazole prescribing by dispensing and non-dispensing doctors: do they differ in rationality?. Tropical Medicine and International Health 7, 10, 878-885.

Trap, B., Hansen, E.H., 2003. Treatment of upper respiratory tract infections - a comparative study of dispensing and non-dispensing doctors. Journal of Clinical Pharmacy and Therapeutics 27, 289-298.

Werneck, G.L., Guilherme, L., Costa, C.H.N., Walker, A.M., David, J.R., Wand, M., and Maguire, J.H., 2002. The urban spread of visceral leishmaniasis: clues from spatial analysis. Epidemiology 13, 364-369. 


\section{Appendix}

\section{Demand for physician consultations}

Let $p_{j}^{c} \in[0,1]$ be the probability of a correct diagnosis by GP $j$. Diagnostic services $\left(e_{j}\right)$ are bounded in the range $e_{j} \in\left[e^{\min }, e^{\max }\right]$ and increase the probability of a correct diagnosis through the following relationship $p_{j}^{c}\left(e_{j}\right)=\beta e_{j}$, with $\beta \in[0,1]$. For simplicity, we set $e^{\min }=0$ and $e^{\max }=1 / \beta$. Both types of infections (viral and bacterial) are equally likely. Hence, $p=p[i=b, v] \equiv 0.5$. Consequently, the probability that the diagnosis is a bacterial infection and an antibiotic is correctly prescribed is $p p_{j}^{c}=\frac{1}{2} \beta e_{j}$. The probability of mistaken diagnosis is $\frac{1}{2}\left(1-\beta e_{j}\right)$.

Since patients split equally between the two practices, doctor $j$ 's total demand for consultations by young patients $(\theta)$ is:

$$
D_{l t}^{y}\left(e_{l t}\right)=\frac{\theta}{2}\left[1+\frac{1}{2}\left(1-\beta e_{l t}\right)\right]
$$

where $\frac{1}{2}\left(1-\beta e_{l t}\right)$ is the proportion of patients with a bacterial infection who need a second consultation because of wrong diagnosis. Similarly, we can write the demand for GP $r$ as $D_{r t}^{y}\left(e_{r t}\right)=\theta\left[1+\left(1-\beta e_{r t}\right) / 2\right] / 2$.

A number of individuals $\phi D_{t-1}^{A y}$ is healthy in the second period, where $\phi \in[0,1]$ is the marginal prevention effect from antibiotic treatment, and $D_{t-1}^{A y}$ is the total number of young patients receiving antibiotics from both GPs in period $t-1$. The total number of young patients receiving antibiotics is obtained by adding the number of patients with a viral infection who receive an antibiotic because of wrong diagnosis, $\frac{\theta}{2} \frac{1}{2}\left(1-\beta e_{l t-1}\right)$, to the total number of young patients with a bacterial infection, $\theta / 2$. Using (13), we get $D_{l t-1}^{A y}\left(e_{l t-1}\right)=\left(D_{l t-1}^{y}-\theta / 4\right)$. Hence, considering both GPs, we obtain: $D_{t-1}^{A y}\left(e_{l t-1}, e_{r t-1}\right)=D_{l t-1}^{A y}+D_{r t-1}^{A y}=D_{l t-1}^{y}+D_{r t-1}^{y}-\theta / 2$

Total demand for consultations for GP $l$ in each period $t$ can be written by summing up the demand for consultations by young and old patients as

$$
D_{l t}\left(e_{l t}, e_{l t-1}, e_{r t-1}\right)=D_{l t}^{y}+\left(\frac{\theta}{2}-\phi D_{t-1}^{A y}\right)\left[1+\frac{1}{2}\left(1-\beta e_{l t}\right)\right] .
$$

The term $\frac{1}{2}\left(1-\beta e_{l t}\right)$ within the squared brackets is the fraction of old patients with a bacterial infection who need a second consultation because of wrong diagnosis. Note that diagnosis effort in period $t-1$ affects demand in the following period through $D_{l t-1}^{y}$. Total second-period demand for GP $r$ can be derived similarly as above. 


\section{The physician's objective function}

Using (14) we can write GP l's intertemporal profit at time $t$ as

$$
\begin{aligned}
V_{l t}= & \sum_{t=k}^{\infty} \delta^{t-k} \pi_{l t}\left(e_{l t}, e_{l t-1}, e_{r t-1}\right) \\
= & \sum_{t=k}^{\infty} \delta^{t-k}\left[(f-c) D_{l t}\left(e_{l t}, e_{l t-1}, e_{r t-1}\right)+(z-\eta) D_{l t}^{A}\left(e_{l t}, e_{l t-1}, e_{r t-1}\right)+\right. \\
& \left.-\rho D_{t-1}^{A y}\left(e_{l t-1}, e_{r t-1}\right)-\gamma e_{l t}^{2}\right]
\end{aligned}
$$

where $\delta \in(0,1]$ is the discount factor for future profits, $f$ is the fixed fee for a consultation, $c$ is the fixed marginal cost of a consultation $(c<f), \gamma$ is the marginal cost of diagnostic services, and $\rho$ is the cost of bacterial resistance generated by each young patient treated with antibiotics in period $t-1$. Note that $D_{l 1}=D_{l 1}^{y}$ since there are only young consumers in the market, and $D_{l 0}^{y}=0$. The expected costs and benefits of dispensing are $(z-\eta) D_{l t}^{A}$, where $z$ is the unit price of drugs dispensed to the patient and $\eta \leq z$ represents the unit cost of drugs on stock. $D_{l t}^{A}=D_{l t}-\left(\theta-\phi D_{t-1}^{A y}\right) / 2$ is the number of antibiotic treatments in period $t$. The number of antibiotic treatments sold is obtained by summing up the number of young and old patients with a bacterial infection (correctly diagnosed), the number of individuals with a viral infection with a wrong diagnosis, and the number of patients who require a second consultation because a bacterial infection was not initially diagnosed. From total demand for consultations, $D_{l t}$, we subtract the number of patients with a correct diagnosis not treated with antibiotics. These are $\theta / 4$ young patients with viral infections and $\left(\theta / 2-\phi D_{t-1}^{A y}\right) / 2$ old patients with viral infections. We simplify equation (15) by setting $c=0$ and $\eta=0$.

\section{Market equilibrium}

A pair of reaction functions $\left(R_{l}\right.$ and $\left.R_{r}\right)$ form a Markov perfect equilibrium if $e_{l t}=$ $R_{l}\left(e_{r t-1}\right)$ maximizes GP l's intertemporal profit at any time, given $e_{r t-1}$ and assuming that GP $l$ will move according to $R_{l}$, and the same holds for GP $r$. To solve for a Markov perfect equilibrium, let $V_{l}\left(e_{r}\right)$ be the present discounted value of GP l's profits given that last period GP $r$ played $e_{r}$ and that from this time forth both GPs play optimally, i.e. according to their Markov strategies, and let $V_{l}\left(e_{l}\right)$ be the present discounted value of GP l's profits given that last period GP $l$ played $e_{l}$ and that hereafter both GPs play optimally. $V_{r}\left(e_{l}\right)$ and $V_{r}\left(e_{r}\right)$ are symmetric. Given that GP $j$ 's choice of $e_{j}$ is 
restricted to a bounded set, the following are necessary and sufficient conditions for the reaction and value functions to be consistent and correspond to an equilibrium: $V_{l}\left(e_{r}\right)=$ $\max _{e_{l}}\left\{\pi_{l}\left(e_{l}, e_{r}\right)+\delta V_{l}\left(e_{l}\right)\right\}=\pi_{l}\left(R_{l}\left(e_{r}\right), e_{r}\right)+\delta V_{l}\left(R_{l}\left(e_{r}\right)\right)$ and $V_{l}\left(e_{l}\right)=\pi_{l}\left(e_{l}, R_{r}\left(e_{l}\right)\right)+$ $\delta V_{l}\left(R_{r}\left(e_{l}\right)\right)$.

Because diagnosis effort affects profits in two subsequent periods and expected profits are the sum of concave functions in $e_{l t}$, we can write the following first-order conditions for GP $l$ - the dynamic reaction function - using (15) as:

$$
\begin{aligned}
\frac{\partial V_{l t}}{\partial e_{l t}} & =\frac{\partial \pi_{l t}\left(\boldsymbol{e}_{l t}, e_{l t-1}^{*}, e_{r t-1}^{*}\right)}{\partial e_{l t}}+\delta \frac{\partial \pi_{l t+1}\left(e_{l t+1}^{*}, \boldsymbol{e}_{l t}, e_{r t}\right)}{\partial e_{l t}} \\
& =f\left[\frac{\partial D_{l t}\left(\boldsymbol{e}_{l t}, e_{l t-1}^{*}, e_{r t-1}^{*}\right)}{\partial e_{l t}}+\delta \frac{\partial D_{l t+1}\left(e_{l t+1}^{*}, \boldsymbol{e}_{l t}, e_{r t}\right)}{\partial e_{l t}}\right]+ \\
& +z\left[\frac{\partial D_{l t}^{A}\left(\boldsymbol{e}_{l t}, e_{l t-1}^{*}, e_{r t-1}^{*}\right)}{\partial e_{l t}}+\delta \frac{\partial D_{l t+1}^{A}\left(e_{l t+1}^{*}, \boldsymbol{e}_{l t}, e_{r t}\right)}{\partial e_{l t}}\right]+ \\
& -\rho \frac{\partial D_{t}^{A y}\left(\boldsymbol{e}_{l t}, e_{r t}\right)}{\partial e_{l t}}-2 \gamma e_{l t}=0
\end{aligned}
$$

and symmetrically for GP $r$. The second-order conditions are $\frac{\partial V_{l t}^{2}}{\partial^{2} e_{l t}}=-2 \gamma<0$. Using (13) and (14) we get $\frac{\partial D_{l t}}{\partial e_{l t}}=-\frac{\beta}{2}\left(\theta-\phi D_{t-1}^{A y}\right)=-\frac{\beta \theta}{2}\left\{1-\phi\left[1-\frac{\beta}{4}\left(e_{l t-1}+e_{r t-1}\right)\right]\right\}$ and $\frac{\partial D_{l t+1}}{\partial e_{l t}}=-\phi\left[1+\frac{1}{2}\left(1-\beta e_{l t+1}\right)\right] \frac{\partial D_{t}^{A y}}{\partial e_{l t}}$. Since $\frac{\partial D_{t}^{A y}}{\partial e_{l t}}=-\frac{\beta \theta}{4}$ we then get $\frac{\partial D_{l t+1}}{\partial e_{l t}}=$ $\frac{\phi \theta \beta}{4}\left[1+\frac{1}{2}\left(1-\beta e_{l t+1}\right)\right]$. We have $\frac{\partial D_{l t}^{A}}{\partial e_{l t}}=\frac{\partial D_{l t}}{\partial e_{l t}}$ and $\frac{\partial D_{l t+1}^{A}}{\partial e_{l t}}=\frac{\partial D_{l t+1}}{\partial e_{l t}}-\frac{1}{2}\left(\theta-\phi \frac{\partial D_{t}^{A y}}{\partial e_{l t}}\right)=$ $\frac{\phi \theta \beta}{4}\left(1-\frac{\beta}{2} e_{l t+1}\right)$. Substituting for $\partial D_{l t} / \partial e_{l t}, \partial D_{l t+1} / \partial e_{l t}, \partial D_{l t}^{A} / \partial e_{l t}, \partial D_{l t+1}^{A} / \partial e_{l t}$, and $\partial D_{t}^{A y} / \partial e_{l t}$ in (16) and solving for the level of diagnostic services assuming for simplicity $\delta=1$ and imposing $\partial V_{l t} / \partial e_{l t}=\partial V_{l t+1} / \partial e_{l t+1}=0$ and $\partial V_{r t} / \partial e_{r t}=\partial V_{r t+1} / \partial e_{r t+1}=0$, we then get the equilibrium level of diagnostic services defined by equation (1) in the main text. 